\title{
Trends in the
} methodological quality of published randomized

\section{controlled trials on antibacterial agents}

\section{Matthew E. Falagas, ${ }^{1,2}$ Eleni I. Pitsouni ${ }^{1}$ \& loannis A. Bliziotis ${ }^{1}$}

${ }^{1}$ Alfa Institute of Biomedical Sciences (AIBS), Athens, Greece and ${ }^{2}$ Department of Medicine, Tufts University School of Medicine, Boston, MA, USA

\section{WHAT IS ALREADY KNOWN ABOUT} THIS SUBJECT

- Randomized controlled trials (RCTs) are believed to be one of the best methods of clinical research because they can minimize systematic errors of various types.

- Temporal trends in the various aspects of RCTs have been studied in several medical fields (e.g. nephrology, hepatology, oncology).

- However, there is lack of data regarding the trends in the methodological quality of RCTs focusing on antimicrobial agents.

\section{WHAT THIS STUDY ADDS}

- Several important methodological aspects of RCTs on antibacterial agents, such as description of randomization, double blinding, description of the blinding and allocation concealment, have not improved during the last 30 years.

\section{AIM} last 30 years.

\section{METHODS}

\section{RESULTS}

\section{Correspondence}

Professor Matthew E. Falagas, MD, MSc, DSc, Alfa Institute of Biomedical Sciences (AIBS), 9 Neapoleos Street, 15123

Marousi, Greece.

Tel: +306946110000

Fax: + 302106839605

E-mail:m.falagas@aibs.gr

Author contributions: M.E.F. had the idea for this article. E.I.P. and I.A.B. collected the relevant data. M.E.F. and E.I.P. wrote parts of the first version of the manuscript. All authors participated in subsequent revisions of the manuscript and approved its final version.

\section{Keywords}

antibiotic, antimicrobial agent, bias, trial

\section{Received}

19 September 2007

Accepted

21 December 2007

Published OnlineEarly

15 February 2008

To investigate the trends of the methodological quality of randomized controlled trials (RCTs) of antimicrobial agents published during the

We randomly selected from the Cochrane Central Register of Controlled Trials database 70 RCTs of antibacterial agents that were published during a 30-year study period (1975-2005); specifically, we randomly selected 10 RCTs published during each of the following years: 1975, 1980, 1985, 1990, 1995, 2000 and 2005. In each of the selected RCTs, we searched for information on various methodological aspects and graded the methodological quality of the RCTs to evaluate trends for possible improvement.

No improvement was noted in most of the analysed methodological aspects of the RCTs during the 30-year study period. Description of randomization, double blinding, description of the blinding, and allocation concealment were rather scarce among the evaluated RCTs, without observing a trend for improvement during the study period. We noted improvement in reporting power of the study calculations, baseline data as well as in reporting the presence or not of statistical significance and the statistical cut-off of significance. In only 1/70 RCTs were all 13 of the examined methodological quality aspects met and in one more RCT 12 of them were met.

\section{CONCLUSIONS}

We did not observe considerable improvement in the quality of the reporting and methodology of RCTs on antibacterial agents during the last 30 years. The methodological quality aspects that need most improvement are those that help safeguard against various types of biases. 


\section{Introduction}

Randomized controlled trials (RCTs) are believed to be one of the best methods of clinical research because they can minimize systematic errors of various types. The British Medical Research Council conducted the first RCT (testing streptomycin for the treatment of tuberculosis) in 1948 [1]. Since then, many researchers have used the RCT methodology in all medical fields. Thus, the scientific community has a lot of interest in performing high-quality RCTs that will provide answers to important clinical questions.

Temporal trends in the various aspects of RCTs have been studied in several medical fields (e.g. nephrology [2], hepatology [3], oncology [4], paediatric [5], cardiothoracic surgery [6] and clinical pharmacology [7]). However, there is lack of data regarding the trends in the methodological quality of RCTs focusing on antimicrobial agents. Hence, the objective of this study was to investigate the possible changes in the reporting and methodological quality of RCTs, focusing on studies of antibacterial drugs that were published from 1975 until 2005.

\section{Methods}

\section{Search strategy}

Using the online Cochrane Central Register of Controlled Trials database (http://www.mrw.interscience.wiley.com/ cochrane/cochrane_central_articles_fs.html, accessed on 3 November 2006), we searched for articles that referred to antibacterial drugs and were published in the years 1975, 1980, 1985, 1990, 1995, 2000 and 2005. The keywords used in our literature searches were: antibacterial, antimicrobial, sulfonamides, aminoglycoside, chloramphenicol, polymyxin, rifampin, lactams, penicillin, cephalosporin, carbapenem, monobactam, macrolide, tetracycline, glycopeptide, lincosamide, quinolone, fluoroquinolone, oxazolidinone and imidazole.

\section{Selection of RCTS}

The initially identified articles were put in an order as they were retrieved from our literature searches (for 1975 from 1 to 180 , for 1980 from 1 to 311 , for 1985 from 1 to 502 , for 1990 from 1 to 636 , for 1995 from 1 to 794 , for 2000 from 1 to 823 , and for 2005 from 1 to 596). Then, using an internet resource for derivation of random numbers (research randomizer; http://www.Randomizer.org), we randomly selected 20 articles for each year of our study $(1975,1980$, $1985,1990,1995,2000$ and 2005), with the intent to review in detail the first 10 studies from each year that qualified for inclusion in our study, e.g. were indeed RCTs focusing on antibacterial agents. Specifically, from the retrieved articles, eligible for further evaluation of the full text and inclusion in our study were those that studied the comparative efficacy and/or safety of antibacterial treatment and included in their title and/or abstract the words randomization, randomly, or random. Articles that referred to pharmacokinetics, or dentistry or veterinary medicine, reported on local antimicrobial therapies, antimicrobial agents other than antibacterials (e.g. antifungal, antiviral or antiparasitic) were excluded from further evaluation, as were non-English language articles.

\section{Evaluation of RCTS}

In order to evaluate the methodological quality of each of the 70 RCTS reviewed (10 per selected year), predefined criteria were used. Specifically, we used a modified version of Jadad (http://www.ncbi.nlm.nih.gov/books/ bv.fcgi?rid=hstat3.section.3039, accessed on 3 November 2006) criteria of evaluating the methodological quality of RCTs as well additional criteria, and we created a point grading system. One of the Jadad criteria was not used, specifically whether the study was described as randomized, because all of the articles included in our analysis were characterized as randomized in their title or abstract, based on our study design. Two of the original Jadad criteria of evaluating the methodological quality of RCTs were used: double blinding, and description of withdrawals and dropouts. In addition, we modified two criteria of the Jadad score (quality of the blinding and quality of the randomization) in order to focus more on the reporting of methodological issues of the RCTs.

Besides these four criteria from the Jadad score, nine additional criteria were used in the evaluation of the methodological quality of the reviewed RCTs. Six of them were selected from the Consolidated Standards of Reporting Trials [CONSORT (http://www.consort-statement.org, accessed on 3 November 2006)]. They mainly focus on the quality of the methodology of RCTs and are about sample size and power of the study, interventions, outcomes, allocation concealment, baseline data and adverse events. We did not use from the CONSORT statement some other criteria of quality of reporting of RCTs, specifically information regarding the scientific background and explanation of rationale, objectives, sequence generation, implementation, statistical methods, participant flow, recruitment, numbers analysed, outcomes and estimation, ancillary analyses, interpretation, generalizability, and overall evidence. Finally, three more criteria in the evaluation of the methodological quality of the reviewed RCTs were used, specifically: adequate reporting of eligibility, statistical significance, and conflicts of interest and funding of the research.

Overall, we aimed at using the most essential and crucial criteria for the quality of studies on antimicrobial agents. The choice was made after consensus of all authors (M.E.F., E.I.P., I.A.B.). In addition, we tried to use clearly defined criteria so that there would be no confusion when evaluating their presence in papers. Two reviewers independently assessed the 70 RCTs. Any disagreement was resolved by consensus. 


\section{Definitions of methodological quality criteria}

Description of randomization Defines the method used to select the random numbers of allocation. One point was added if it was reported in detail, e.g. 'randomization sequence was generated by a computerized system'. Zero points were added if no data were provided regarding details of randomization.

Double blind method If the authors reported that the study was double blind (in which both the participant and the investigator are unaware of the regimen assigned to each participant), one point was added, if not 0 points.

Description of blinding Specifies the method used for the assurance of blinding. One point was added if the blinding was reported in detail, e.g. 'identical yellow tablets were used in both groups'. Zero points were added if there were no data provided regarding details of the blinding.

Description of withdrawals and drop-outs Defines the number of participants and the specific reason that led them to withdrawal and drop-out from the study. If both were reported in detail, one point was added, and if it was not, 0 points.

Eligibility of the study group Specifies criteria that qualify persons to enter the study. One point was added if the inclusion and exclusion criteria were reported in detail, and 0 points if they were not.

Interventions Defines specific details of the study drugs dosing, including the route of administration and the duration of therapy. One point was added if the description was adequate, and 0 points if not.

Outcomes One point was added if primary and secondary outcomes were clearly defined in the introduction and in the methods section of the article; if not, 0 points were added.

Allocation concealment [8] Defines the method of maintaining concealment of participant assignment until at least the point of treatment allocation. One point was added if the allocation concealment was mentioned and the description was adequate, e.g. centralized or pharmacy-controlled allocation with prenumbered/ sequentially numbered, sealed, opaque envelopes. Zero points were added if the approaches to allocation concealment were not reported.

Baseline data One point was added when demographic characteristics, risk factors, or underlying diseases for each group were described and 0 points when no data were provided.
Adverse events One point was added if adverse events or side-effects were reported in each group and 0 points if they were not.

Power of the study - sample size calculation The description of the mathematical approach for calculating the statistical power of the study or the number of participants needed in each study group, in order to have sufficient statistical power (e.g. $=80 \%$ ) to answer the research question. One point was added when there was power of the study calculation or presentation of the sample size calculation.

Statistical significance One point was added if in the results section of the article, details regarding the presence or not of statistical significance, as well as the exact result of the statistical testing (expressed as P-value or a confidence interval, for example) were reported. In case there were no data provided in the results section or there was only a report of the statistical methods used, in the methods section of the article, 0 points were added.

Conflicts of interest and funding of the research If the authors reported that the study was sponsored (or nonsponsored), 1 point was added; 0 points were added if there was lack of information regarding the financial support of the clinical trial.

\section{Results}

The 70 studies reviewed in our paper presented some degree of variability regarding the country of origin, the infections and therapies studies and, finally, their methodological characteristics. Most of the RCTs originated from the USA [23/70 (32.9\%)], USA with other countries [5/70 $(7.1 \%)]$, UK [6/70 (8.6\%)] and UK with other countries [4/70 (5.7\%)]. Only one of the 70 reviewed and analysed RCTs (originating from the USA and published in 1995) met all of the methodological quality criteria evaluated in this study.

A considerable variety of infections was studied in the reviewed $\mathrm{RCTs}$, including respiratory tract, abdominal tract and urinary tract infections as well as infections caused by specific organisms such as tuberculosis, typhoid fever, syphilis, gonorrhea, as well as Helicobacter pylori infection. Although some small trends were noted (e.g. H.pylori infection was studied in more recent studies), there was no obvious bias regarding the types of infections studied over the years. Similarly, although, as expected, $\beta$-lactams and macrolides were the most commonly studied antibiotics, there was no clear clustering of a specific antibiotic within any of the study periods.

In Table 1 we present the summary data regarding the 13 evaluated methodological quality criteria for the 70 reviewed RCTs (10 in each of the 7 years studied). Overall, there were only four disagreements between the two reviewers regarding the methodological evaluation, which 


\section{Table 1}

Methodological quality criteria evaluated of randomly selected randomized controlled trials (RCTs) published during the 30-year study period*

\begin{tabular}{|c|c|c|c|c|c|c|c|}
\hline & $\begin{array}{l}1975 \\
(n=10)\end{array}$ & $\begin{array}{l}1980 \\
(n=10)\end{array}$ & $\begin{array}{l}1985 \\
(n=10)\end{array}$ & $\begin{array}{l}1990 \\
(n=10)\end{array}$ & $\begin{array}{l}1995 \\
(n=10)\end{array}$ & $\begin{array}{l}2000 \\
(n=10)\end{array}$ & $\begin{array}{l}2005 \\
(n=10)\end{array}$ \\
\hline \multicolumn{8}{|l|}{ Jadad criteria (modified) } \\
\hline Double blinding & 5 & 2 & 3 & 4 & 3 & 3 & 3 \\
\hline Description of blindingt & 2 & 2 & 2 & 3 & 3 & 3 & 2 \\
\hline Description of withdrawals and drop-outs & 7 & 4 & 5 & 3 & 8 & 8 & 7 \\
\hline \multicolumn{8}{|l|}{ Additional criteria } \\
\hline Outcomes & 10 & 10 & 10 & 10 & 10 & 10 & 10 \\
\hline Allocation concealment & 4 & 1 & 3 & 2 & 5 & 2 & 2 \\
\hline Baseline data & 7 & 9 & 8 & 10 & 10 & 10 & 10 \\
\hline Adverse events & 9 & 8 & 7 & 8 & 7 & 10 & 7 \\
\hline Power of the study & 0 & 0 & 0 & 1 & 3 & 4 & 4 \\
\hline Statistical significance & 5 & 6 & 9 & 7 & 10 & 10 & 8 \\
\hline
\end{tabular}

*Numbers in the columns denote the result of the methodological quality of the evaluated RCTs based on the grading system we used and explained in Methods. †The numbers regarding quality of blinding should be interpreted in relation to the numbers of trials which were double blind [e.g. in 1975 2/5 (40\%) of maximum points for double blinding were given, vs. $2 / 2$ in $1980(100 \%)]$.

were solved in a consensus meeting. No improvement was noted in most of the methodological quality criteria (from 1975 to 2005). The proportion of the reviewed RCTs with good reporting of randomization ranged from two in 10 to six in 10 RCTs in different years studied, with double blinding from two in 10 to five in 10 RCTs, good reporting of the blinding from two in five to three in three RCTs, and with allocation concealment from one in 10 to five in 10 RCTs.

An improvement was noted during the 30-year study period regarding three methodological quality criteria of the studied RCTs; specifically, reporting power of the study (from 0 in 10 RCTs to four in 10 RCTs in successive studied years during the study period), details regarding the presence or not of statistical significance and the statistical cut-off of significance (from five in 10 RCTs to 10 in 10 RCTs in successive studied years during the study period), and description of baseline data (from seven in 10 to 10 in 10 RCTs during the study period). All reviewed RCTs during the 30-year period reported details regarding eligibility of the study groups, interventions and outcomes. Description of withdrawals and drop-outs ranged from three in 10 to eight in 10 RCTs, whereas it ranged from seven in 10 to 10 in 10 RCTs for adverse events and from four in 10 to nine in 10 RCTs for reporting conflicts of interest and funding of the research.

\section{Discussion}

The most noteworthy finding of our study is that several methodological quality and quality of reporting aspects of RCTs on antibacterial agents have not improved during the 30-year study period (1975-2005). Specifically, no improvement was noted in four important methodological quality criteria: description of randomization, double blinding, description of blinding, and allocation concealment. It should be emphasized that these methodological aspects of RCTs are of major significance because they ensure minimization of various sources of bias; thus the finding that RCTs have not improved regarding these characteristics during the last years cannot be ignored.

In addition, inadequate improvement was noted regarding another important methodological quality criterion: description of withdrawals. Furthermore, not all evaluated RCTs reported adverse events and conflicts of interest/source of funding. Adequate reporting of information regarding these three methodological criteria is also crucial for understanding important aspects of RCTs and interpreting the research findings. An interesting observation was that there was correlation between reporting adverse events and description of withdrawals or dropouts, a probably expected finding (data not shown).

Improvement during the 30-year study period was noted in only three methodological quality criteria: reporting of the power of the study, reporting baseline data and reporting the presence or not of statistical significance and the statistical cut-off of significance. Specifically, fewer RCTs during the early years of the study reported information regarding baseline characteristics of the enrollees and, when this happened, they usually reported information for one or two characteristics (mainly sex and age), whereas in articles of RCTs performed later long tables, including up to 20 baseline characteristics of enrollees, were common. Such characteristics frequently included demographic data, risk factors, underlying morbidity and socioeconomic status. This finding may indicate a more extensive and detailed collection of patient baseline data rather than simply a better reporting of them in research papers. It is unknown to what degree the noted improvement in base- 
line data reporting is the result of the development of electronic research databases that allow easier handling of extensive datasets.

Regarding reporting the presence or not of statistical significance and the statistical cut-off of significance, an improvement was also observed during the study period: $28 / 30$ vs. $27 / 40$ articles during $1995-2005$ and $1975-1990$, respectively, reported details regarding the statistical analysis. This finding depicts the fact that simply reporting results without mentioning their statistical significance does not offer substantial evidence in current medical research and practice. Similarly, details on calculations of the power of the study/study sample size have been more commonly reported in recent years. Of note, they were reported in only 13 of the reviewed 70 studies and in none prior to 1990.

Adequate description was noted during the whole 30-year study period regarding three methodological quality criteria: eligibility of the study group, interventions, and outcomes. However, this is not surprising, since these characteristics are considered basic information of an RCT and, thus, reporting details regarding them does not mean that an RCT is necessarily of high quality. In this context, many medical journals and especially the so-called core journals require specific check lists with characteristics that should be included (or reported) in any study that is submitted for publication to them, in an attempt to help authors improve the quality and the quality of reporting of RCTs.

Our analysis has several limitations. First, it should be emphasized that the quality of reporting methodological aspects of research does not fully match the quality of the performed research itself. However, there is definitely significant overlapping between these two ideas. Although several factors can affect the quality of reporting of research, it is clear that for most of the methodological parameters examined in this paper, reporting them by the authors equals having performed them and vice versa. It is unclear why somebody would design an RCT on antibacterial agents and collect relevant data, but nevertheless would not report, for example, eligibility criteria, interven- tions, outcomes, baseline data, adverse events and withdrawals. However, it should be noted that there might be rare occasions when, due to paper length restrictions or decreased requirements from a journal, this could occur.

A second limitation is that someone could have selected another set of methodological quality criteria to evaluate. However, we selected criteria that are frequently used by the scientific community as characteristics that are important in deriving safe conclusions from an RCT and research findings with applicability in clinical practice. Third, we acknowledge that another grading system of the various methodological quality criteria that we used to evaluate the reviewed RCTs could be supported as more practical and/or valid. We acknowledge that we did not test the reproducibility of the point grading system used in our analysis. Fourth, we included in our analysis 70 RCTs. It should be acknowledged that a larger sample size would allow safer conclusions, but we believe that the number of evaluated RCTs is probably sufficient to support the qualitative statement that more attention should be paid to various methodological quality aspects of RCTs in the field of antimicrobial agents. Fifth, we included only RCTs focusing on antibacterial agents without examining RCTs studying other antimicrobial agents. However, there is no reason to believe that RCTs on antiviral, antifungal and antiparasitic agents would have more methodological quality compared with those focusing on antibacterial agents and performed during the same period. Sixth, we classified the reviewed RCTs based on the year of publication without taking into account the year of initiation of the study.

\section{Conclusion}

In summary, the findings of our mainly descriptive study suggest that several important methodological and reporting aspects of RCTs on antibacterial agents have not improved during the last 30 years. We believe that efforts to increase the methodological quality of RCTs, at least in the studied field of clinical research on antibacterial agents, are warranted. 


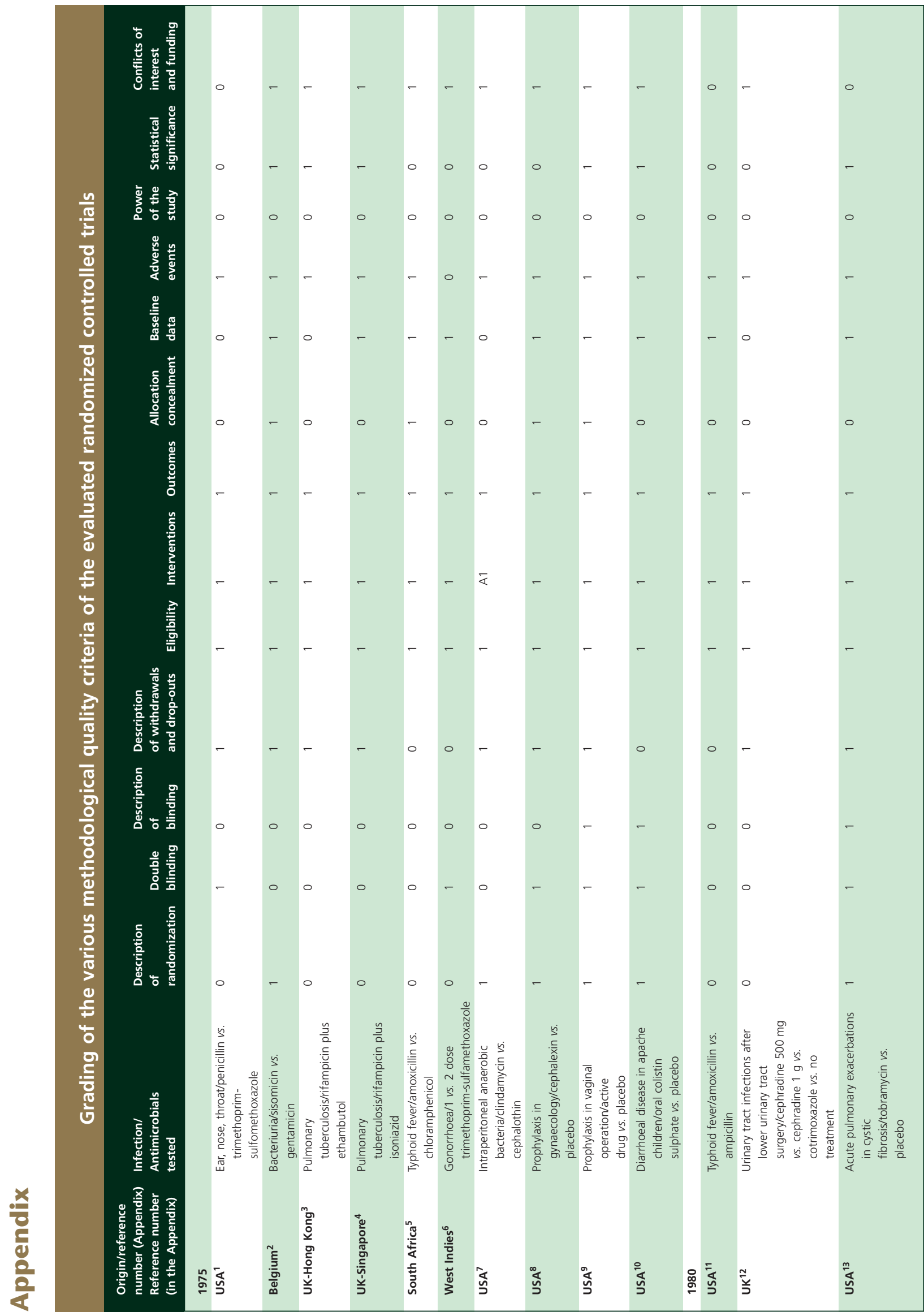


B] CP M. E. Falagas et al.

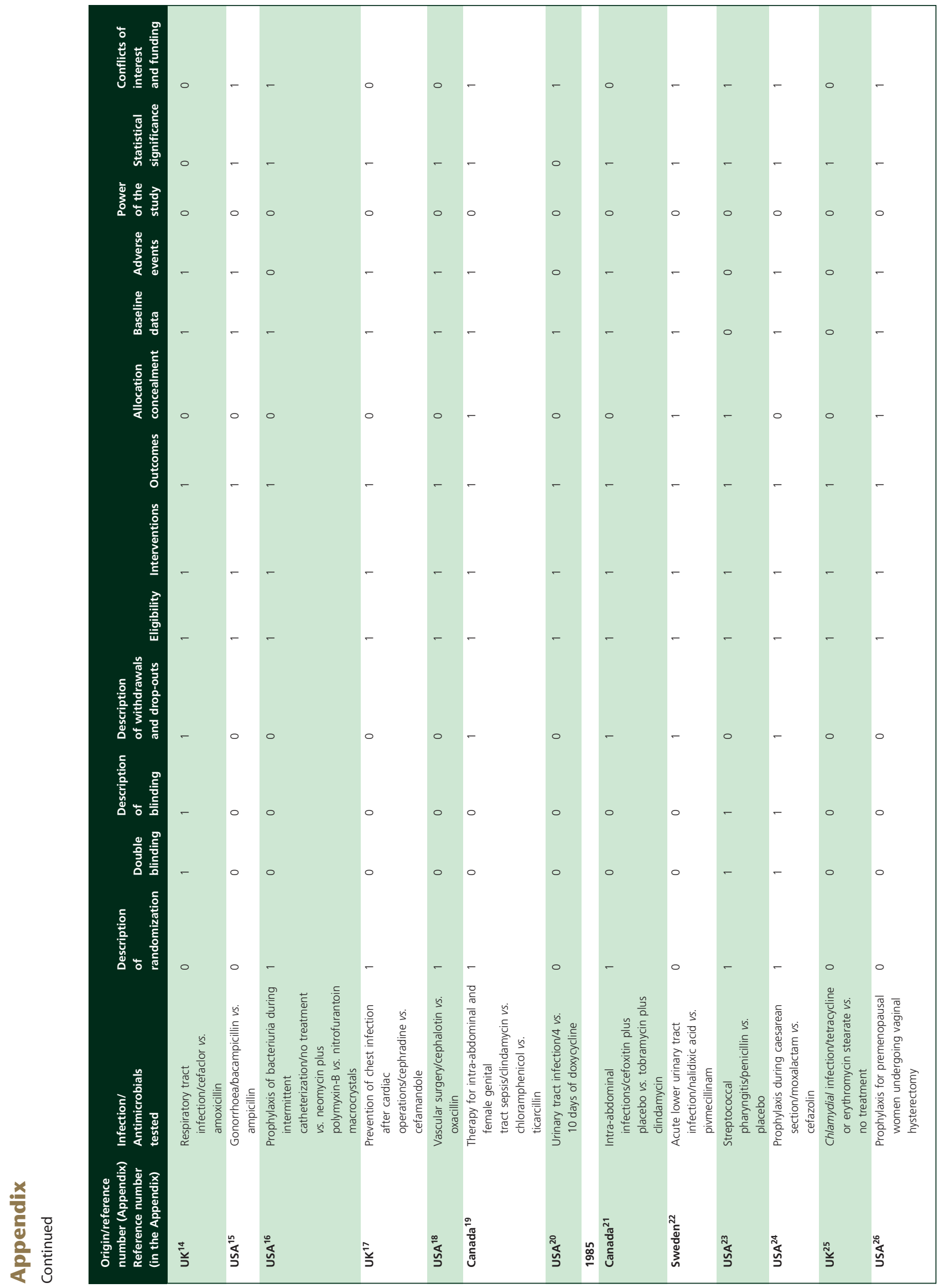




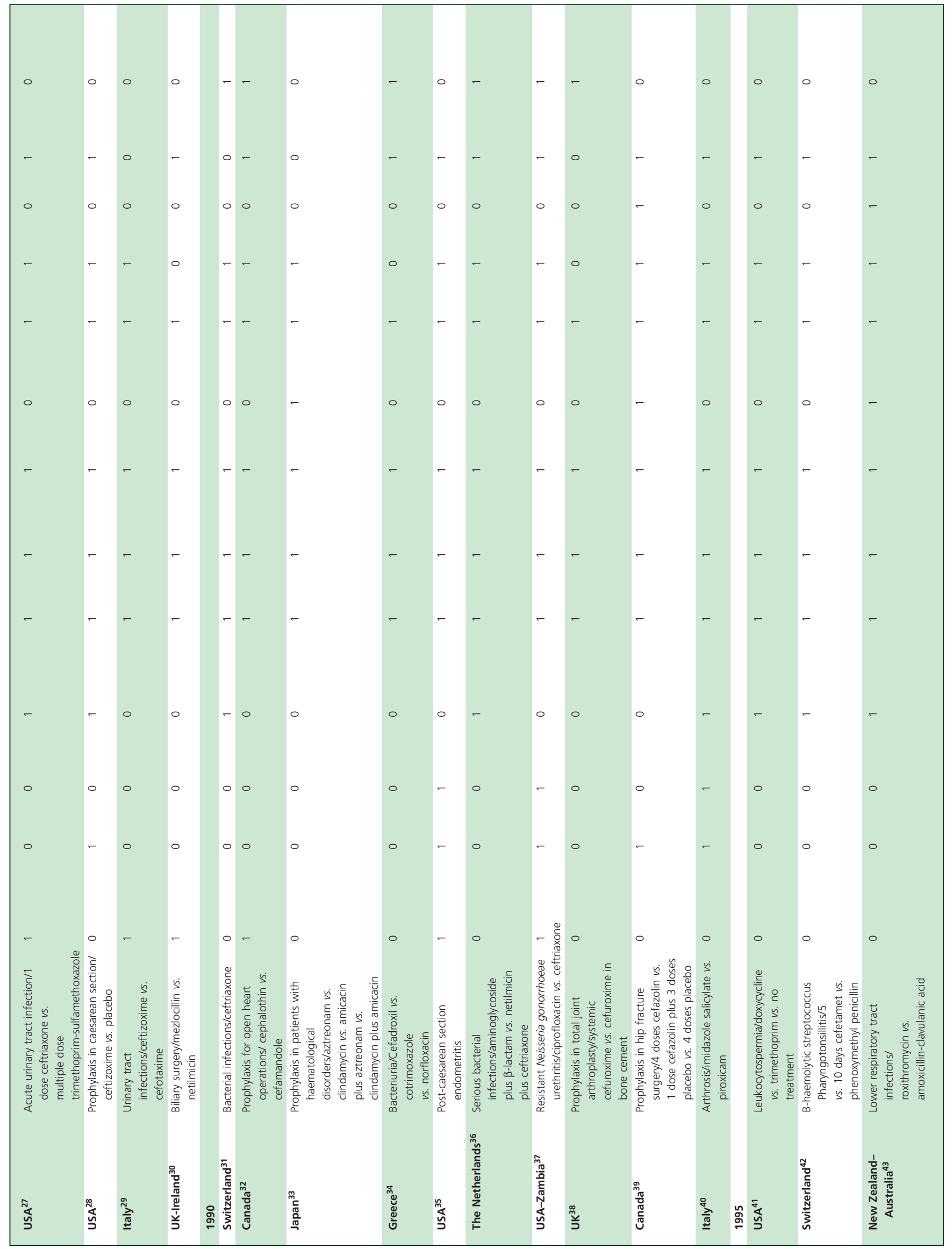


B] CP M. E. Falagas et al.

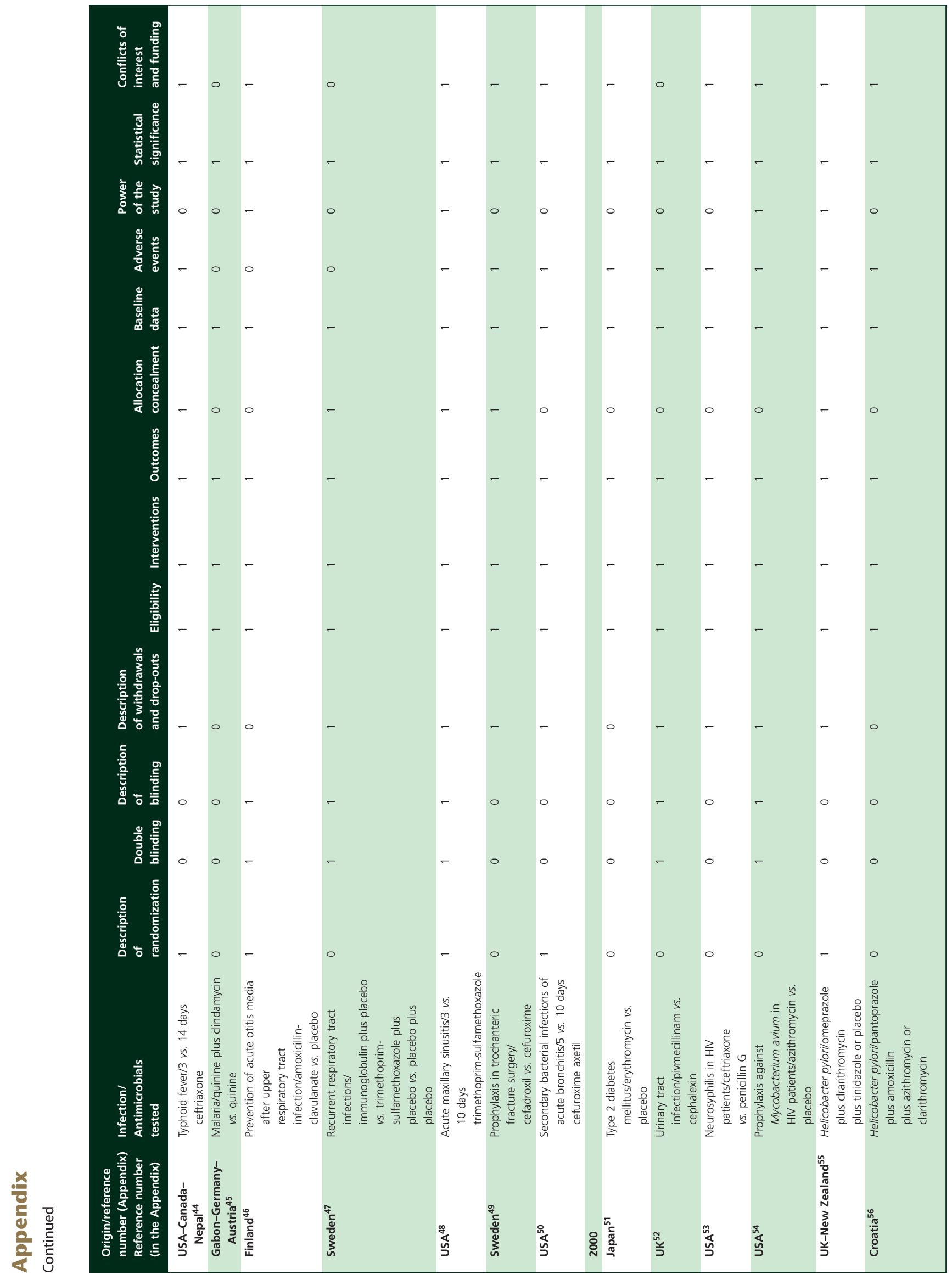




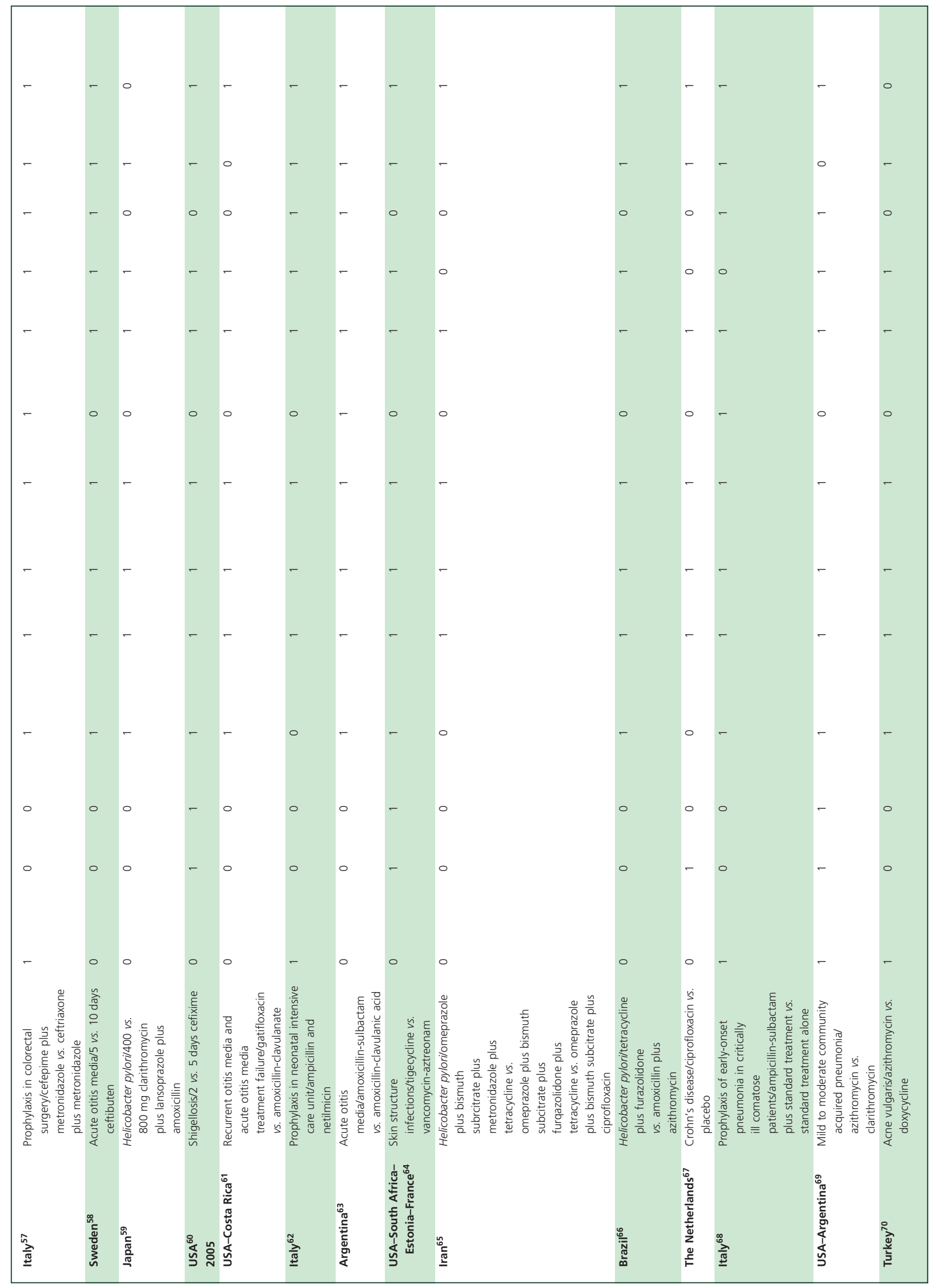




\section{List of references of the randomized controlled} trials evaluated

1 Quick CA. Comparison of penicillin and trimethoprimsulfamethoxazole in the treatment of ear, nose and throat infections. Can Med Assoc J 1975; 112: 83-6.

2 Klastersky J, Hensgens C, Gerard M, Daneau D. Comparison of sisomicin and gentamicin in bacteriuric patients with underlying diseases of the urinary tract. Antimicrob Agents Chemother 1975; 7: 742-7.

3 British Medical Research Council, Hong Kong tuberculosis treatment services. A controlled trial of daily and intermittent rifampicin plus ethambutol in the retreatment of patients with pulmonary tuberculosis: results up to 30 months. Tubercle 1975; 56: 179-89.

4 British Medical Research Council, Singapore tuberculosis service. Controlled trial of intermittent regimens of rifampicin plus isoniazid for pulmonary tuberculosis in Singapore. Lancet 1975; 2: 1105-9.

5 Pillay N, Adams EB, North-Coombes D. Comparative trial of amoxycillin and chloramphenicol in treatment of typhoid fever in adults. Lancet 1975; 2: 333-4.

6 Brathwaite AR. Treatment of gonorrhea in the male with trimethoprim-sulfamethoxazole using a one- or twodose regimen. Can Med Assoc J 1975; 112: 40S-42S.

7 Stone HH, Kolb LD, Geheber CE. Incidence and significance of intraperitoneal anaerobic bacteria. Ann Surg 1975; 181: 705-15.

8 Ledger WJ, Gee C, Lewis WP. Guidelines for antibiotic prophylaxis in gynecology. Am J Obstet Gynecol 1975; 121: 1038-45.

$9 \mathrm{Ohm} \mathrm{MJ,} \mathrm{Galask} \mathrm{RP.} \mathrm{The} \mathrm{effect} \mathrm{of} \mathrm{antibiotic} \mathrm{prophylaxis}$ on patients undergoing vaginal operations. I. The effect on morbidity. Am J Obstet Gynecol 1975; 123: 590-6.

10 Hirschhorn N, Woodward WE, Evans LL. Attempted prevention of diarrheal disease in Apache children with a non-absorbable broad-spectrum antimicrobial. Am J Trop Med Hyg 1975; 24: 320-5.

11 Howard JB, Aguirre X, Palombo G. Amoxicillin versus ampicillin for treatment of typhoid fever in children. Curr Therap Res 1980; 28: 491-7.

12 Evans CM, Clarke TK, Barnouti H, Crosby AC, Holmes S, Kulatilake $A E$. A controlled trial of different treatment regimens in patients with urinary tract infections after lower urinary tract surgery. Curr Med Res Opin 1980; 6: 386-92.

13 Wientzen R, Prestidge CB, Kramer RI, McCracken GH, Nelson JD. Acute pulmonary exacerbations in cystic fibrosis. A double-blind trial of tobramycin and placebo therapy. Am J Dis Child 1980; 134: 1134-8.

14 Brodie NH, McGhie RL, O'Hara H, O'Hara J, Rahman MK, Vallé-Jones JC. A double-blind study comparing cefaclor and amoxycillin in the treatment of respiratory tract infections in general practice. Pharmatherapeutica 1980; 2: 494-8.

15 Spengler PJ, Edwards LD. Comparative study of bacampicillin and ampicillin in the treatment of uncomplicated gonorrhoea. $\mathrm{Br} J$ Vener Dis 1980; 56: 151-5.

16 Anderson RU. Prophylaxis of bacteriuria during intermittent catheterization of the acute neurogenic bladder. J Urol 1980; 123: 364-6.

17 Galland RB, Shama DM, Prenger KB, Darrell JH. Perioperative antibiotics in the prevention of chest infection following cardiac operations. Br J Surg 1980; 67: 97-8.

18 May ARL, Darling RC, Brewster DC, Darling CS. A comparison of the use of cephalothin and oxacillin in vascular surgery. Arch Surg 1980; 115: 56-9.

19 Harding GMK, Buckwold FJ, Ronald AR. Prospective, randomized comparative study of clindamycin, chloramphenicol, and ticarcillin, each in combination with gentamicin, in therapy for intraabdominal and female genital tract sepsis. J Infect Dis 1980; 142: 38493.

20 Lockey JE, Williams DN, Raij L, Sabath LD. Comparison of 4 and 10 days of doxycycline treatment for urinary tract infection. J Urol 1980; 124:643-5.

21 Malangoni MA, Condon RE, Spiegel CA. Treatment of intra-abdominal infections is appropriate with a singleagent or combination antibiotic therapy. Surgery 1985; 98: 648-55.

22 Hovelius B, Mardh PA, Nygaard-Pedersen L, Wathne B. Nalidixic acid and pivmecillinam for treatment of acute lower urinary tract infections. Scand J Prim Health Care 1985; 3: 227-32.

23 Krober MS, Bass JW, Michels GN. Streptococcal pharyngitis. Placebo-controlled double-blind evaluation of clinical responses to penicillin therapy. JAMA 1985; 253: 1271-4.

24 Rayburn W, Varner M, Galask R, Petzold CR, Piehl E. Comparison of moxalactam and cefazolin as prophylactic antibiotics during cesarean section. Antimicrob Agents Chemother 1985; 27: 337-9.

25 Maiti H, Haye KR. Does detection of chlamydial antibodies by microimmunofluorescence help in managing chlamydial lower genital tract infection in women? Genitourin Med 1985; 61: 172-4.

26 Hemsell DL, Hemsell PG, Nobles BJ. Doxycycline and cefamandole prophylaxis for premenopausal women undergoing vaginal hysterectomy. Surg Gynecol Obstet 1985; 161:462-4.

27 Iravani A, Richard GA. Single-dose ceftriaxone versus multiple-dose trimethoprim-sulfamethoxazole in the treatment of acute urinary tract infections. Antimicrob Agents Chemother 1985; 27: 158-61.

28 Saltzman DH, Eron LJ, Kay HH, Sites JG. Single-dose antibiotic prophylaxis in high-risk patients undergoing cesarean section. Obstet Gynecol 1985; 65: 655-7.

29 Tripi M, Pavone-Macaluso M, Giammanco A, Carella G. Randomized comparative trial with ceftizoxime and cefotaxime in urinary tract infections. Int Urol Nephrol 1985; 17: 195-202. 
30 Gillen P, Ryan W, Peel AGL. A prospective randomised controlled trial of mezlocillin versus netilmicin in biliary surgery. Ann R Coll Surg Engl 1985; 67: 376-8.

31 Cometta A, Gallot-Lavallee-Villars S, Iten A, Cantoni L, Anderegg A, Gonvers JJ, Glauser MP. Incidence of gallbladder lithiasis after ceftriaxone treatment. J Antimicrob Chemother 1990; 25: 689-95.

32 Miedzinski LJ, Callaghan JC, Fanning EA, Gelfand ET, Goldsand G, Modry D, Penkoske P, Preiksaitis J, Sheehan $\mathrm{G}$, Sterns L. Antimicrobial prophylaxis for open heart operations. Ann Thorac Surg 1990; 50: 800-7.

33 Takemoto Y, Kanamaru A, Nagai K, Masaoka T, Kitani T, Horiuchi A, Yonezawa T, Yasunaga K, Kageyama T, Tatsumi N, Kawagoe H, Akasaka K, Nakayama S, Ohnisi N. Randomized trial of combination antibiotic therapy in patients with hematological disorders. Hanshin Study Group of Hematopoietic Disorders and Infection. Jpn J Antibiot 1990; 43: 63-9.

34 Tzias V, Dontas AS, Petrikkos G, Papapetropoulou M, Dracopoulos J, Giamarellou H. Three-day antibiotic therapy in bacteriuria of old age. J Antimicrob Chemother 1990; 26: 705-11.

35 Hillier S, Watts DH, Lee MF, Eschenbach DA. Etiology and treatment of post-cesarean-section endometritis after cephalosporin prophylaxis. J Reprod Med 1990; 35: 322-8.

36 Ter Braak EW, de Vries PJ, Bouter KP, Ter Braak EW, de Vries PJ, Bouter KP, van der Vegt SG, Dorrestein GC, Nortier JW, van Dijk A, Verkooyen RP, Verbrugh HA. Once-daily dosing regimen for aminoglycoside plus beta-lactam combination therapy of serious bacterial infections: comparative trial with netilmicin plus ceftriaxone. Am J Med 1990; 89: 58-66.

37 Bryan JP, Hira SK, Brady W, Luo N, Mwale C, Mpoko G, Krieg R, Siwiwaliondo E, Reichart C, Waters C, Perine PL. Oral ciprofloxacin versus ceftriaxone for the treatment of urethritis from resistant Neisseria gonorrhoeae in Zambia. Antimicrob Agents Chemother 1990; 34: 81922.

38 McQueen MM, Hughes SPF, May P, Verity L. Cefuroxime in total joint arthroplasty. Intravenous or in bone cement. J Arthroplasty 1990; 5: 169-72.

39 Buckley R, Hughes GN, Snodgrass T, Huchcroft SA. Perioperative cefazolin prophylaxis in hip fracture surgery. Can J Surg 1990; 33: 122-7.

40 Montrone F, Petrillo M, Ardizzone S, Scaricabarozzi I, Scotti A, Caruso I, Bianchi Porro G. Imidazole salicylate versus piroxicam in the treatment of arthrosis in elderly patients. A double-blind clinical and endoscopic trial. J Am Geriatr Soc 1990; 38: 985-8.

41 Yanushpolsky EH, Politch JA, Hill JA, Anderson DJ. Antibiotic therapy and leukocytospermia: a prospective, randomized, controlled study. Fertil Steril 1995; 63: 142-7.

42 Gervaix A, Brighi L, Halpérin DS, Suter S. Cefetamet pivoxil in the treatment of pharyngotonsillitis due to group A beta-hemolytic streptococci: preliminary report. J Chemother 1995; 7 (Suppl. 1): 21-4.

43 Karalus NC, Garrett JE, Lang SDR, et al. Roxithromycin $150 \mathrm{mg}$ b.i.d. versus amoxycillin $500 \mathrm{mg} /$ clavulanic acid $125 \mathrm{mg}$ t.i.d. for the treatment of lower respiratory tract infections in general practice. Infection 1995; 23 (Suppl. 1): S15-20.

44 Acharya G, Butler T, Ho M, Sharma PR, Tiwari M, Adhikari RK, Khagda JB, Pokhrel B, Pathak UN. Treatment of typhoid fever: randomized trial of a three-day course of ceftriaxone versus a fourteen-day course of chloramphenicol. Am J Trop Med Hyg 1995; 52: 1625.

45 Kremsner PG, Radloff P, Metzger W, Wildling E, Mordmüller B, Philipps J, Jenne L, Nkeyi M, Prada J, Bienzle U, Graninger W. Quinine plus clindamycin improves chemotherapy of severe malaria in children. Antimicrob Agents Chemother 1995; 39: 1603-5.

46 Heikkinen T, Ruuskanen O, Ziegler T, Waris M, Puhakka H. Clinical and laboratory observations. Short-term use of amoxicillin- clavulanate during upper respiratory tract infection for prevention of acute otitis media. J Pediatr 1995; 126: 313-6.

47 Nydahl-Persson K, Petterson A, Fasth A. A prospective, double-blind, placebo-controlled trial of i.v. immunoglobulin and trimethoprim-sulfamethoxazole in children with recurrent respiratory tract infections. Acta Paediatr 1995; 84: 1007-9.

48 Williams JW, Holleman DR, Samsa GP, Simel DL. Randomized controlled trial of 3 vs 10 days of trimethoprim/ sulfamethoxazole for acute maxillary sinusitis. JAMA 1995; 273: 1015-21.

49 Nungu KS, Olerud C, Rehnberg L, Larsson S, Nordell P, Allvin I, Bengtsson S, Wallinder L, Hedin G. Prophylaxis with oral cefadroxil versus intravenous cefuroxime in trochanteric fracture surgery. A clinical multicentre study. Arch Orthop Trauma Surg 1995; 114: 303-7.

50 Henry D, Ruoff GE, Rhudy J, Puopolo A, Drehobl M, Schoenberger J, Giguere G, Collins JJ. Effectiveness of short-course therapy ( 5 days) with cefuroxime axetil in treatment of secondary bacterial infections of acute bronchitis. Antimicrob Agents Chemother 1995; 39: 2528-34.

51 Ueno N, Inui A, Asakawa A, Takao F, Tani S, Komatsu Y, Itoh Z, Kasuga M. Erythromycin improves glycaemic control in patients with Type II diabetes mellitus. Diabetologia 2000; 43: 411-5.

52 Menday AP. Comparison of pivmecillinam and cephalexin in acute uncomplicated urinary tract infection. Int J Aantimicrob Agents 2000; 13: 183-7.

53 Marra CM, Boutin P, McArthur JC, Hurwitz S, Simpson PA, Haslett JA, van der Horst C, Nevin T, Hook EW 3rd. A pilot study evaluating ceftriaxone and penicillin $G$ as treatment agents for neurosyphilis in human immunodeficiency virus-infected individuals. Clin Infect Dis 2000; 30: 540-4. 
54 El-Sadr WM, Burman WJ, Grant LB, Grant LB, Matts JP, Hafner R, Crane L, Zeh D, Gallagher B, Mannheimer SB, Martinez A, Gordin F. Discontinuation of prophylaxis against Mycobacterium avium complex disease in HIVinfected patients who have a response to antiretroviral therapy. N Engl J Med 2000; 342: 1085-92.

55 Moayyedi P, Feltbower R, Crocombe W, Mason S, Atha P, Brown J, Dowell AC, Richards ID, Axon AT. The effectiveness of omeprazole, clarithromycin and tinidazole in eradicating Helicobacter pylori in a community screen and treat programme. Aliment Pharmacol Ther 2000; 14: 719-28.

56 Vcev A, Stimac D, Ivandic A, Vceva A, Takac B, Pezerovic D. Pantoprazole, amoxycillin and either azithromycin or clarithromycin for eradication of Helicobacter pylori in duodenal ulcer. Aliment Pharmacol Ther 2000; 14: 69-72.

57 Zanella E, Rulli F. A multicenter randomized trial of prophylaxis with intravenous cefepime + metronidazole or ceftriaxone + metronidazole in colorectal surgery. The 230 Study Group. J Chemother 2000; 12: 63-71.

58 Roos K, Larsson P. Efficacy of ceftibuten in 5 versus 10 days treatment of recurrent acute otitis media in children. Int J Pediatr Otorhinolaryngol 2000; 55: 109-15.

59 Miwi H, Murai T, Sato K, Ohkura R, Yamada T, Nagahara A, Ohtaka K, Minowa T, Kurosawa A, Sato N. Comparison of the efficacy of $400 \mathrm{mg}$ and $800 \mathrm{mg}$ of clarithromycin used with lansoprazole and amoxicillin in eradication regimens for Helicobacter pylori infection in a Japanese population. J Gastroenterol 2000; 35: 536-9.

60 Martin JM, Pitetti R, Maffei F, Tritt J, Smail K, Wald ER. Treatment of shigellosis with cefixime: two days vs. five days. Pediatr Infect Dis J 2000; 19:522-6.

61 Sher L, Arguedas A, Husseman M, Pichichero M, Hamed KA, Biswas D, Pierce P, Echols R. Randomized, investigator-blinded, multicenter, comparative study of gatifloxacin versus amoxicillin/clavulanate in recurrent otitis media and acute otitis media treatment failure in children. Pediatr Infect Dis J 2005; 24: 301-8.

62 Auriti C, Rava L, Di Ciommo V, Ronchetti MP, Orzalesi M. Short antibiotic prophylaxis for bacterial infections in a neonatal intensive care unit: a randomized controlled trial. J Hosp Infect 2005; 59: 292-8.

63 Casellas JM Jr, Israele V, Marín M, Ishida MT, Heguilen R, Soutric J, Arenoso H, Sibbald A, Stamboulian D. Amoxicillin-sulbactam versus amoxicillin-clavulanic acid for the treatment of non-recurrent-acute otitis media in Argentinean children. Int J Pediatr Otorhinolaryngol 2005; 69: 1225-33.

64 Breedt J, Teras J, Gardovskis J, Maritz FJ, Vaasna T, Ross DP, Gioud-Paquet M, Dartois N, Ellis-Grosse EJ, Loh E; Tigecycline 305 cSSSI Study Group. Safety and efficacy of tigecycline in treatment of skin and skin structure infections: results of a double-blind phase 3 comparison study with vancomycin-aztreonam. Antimicrob Agents Chemother 2005; 49: 4658-66.
65 Amini M, Khedmat H, Yari F. Eradication rate of Helicobacter pylori in dyspeptic patients. Med Sci Monit 2005; 11: CR193-5.

66 Frota LC, da Cunha Mdo PSS, Luz CRL, de Araujo-Filho AH, Frota LAS, Braga LLBC. Helicobacter pylori eradication using tetracycline and furazolidone versus amoxicillin and azithromycin in lansoprazole based triple therapy: an open randomized clinical trial. Arquiv Gastroenterol 2005; 42: 111-5.

67 West RL, Van der Woude CJ, Endtz HP, Hansen BE, Ouwedijk M, Boelens HA, Kusters JG, Kuipers EJ. Perianal fistulas in Crohn's disease are predominantly colonized by skin flora: implications for antibiotic treatment? Dig Dis Sci 2005; 50: 1260-3.

68 Acquarolo A, Urli T, Perone G, Giannotti C, Candiani A, Latronico N. Antibiotic prophylaxis of early onset pneumonia in critically ill comatose patients. A randomized study. Intensive Care Med 2005; 31:510-6.

69 Drebobl MA, DeSalvo MC, Lewis DE, Breen JD. Single dose azithromycin microspheres vs clarithromycin extended release for treatment of mild-to-moderate community-acquired pneumonia in adults. Chest 2005; 128: 2230-7.

70 Kus S, Yucelten D, Aytug A. Comparison of efficacy of azithromycin vs. doxycycline in the treatment of acne vulgaris. Clin Exp Dermatol 2005; 30: 215-20.

\section{REFERENCES}

1 British Medical Research Council. Streptomycin treatment of pulmonary tuberculosis. BMJ 1948; 2: 769-82.

2 Strippoli FMG, Craig CJ, Schena PF. The number, quality, and coverage of randomized controlled trials in nephrology. J Am Soc Neprol 2004; 15:411-9.

3 Kjaergard LL, Nikolova D, Gluud C. Randomized clinical trials in hepatology: predictor of quality. Hepatology 1999; 30: 1134-8.

4 Lai R, Chu R, Fraumeni M, Thabane L. Quality of randomized controlled trials reporting in the primary treatment of brain tumors. J Clin Oncol 2006; 24: 1136-44.

5 Anttila H, Malmivaara A, Kunz R, Autti-Ramo I, Makela M. Quality of reporting of randomized, controlled trails in cerebral palsy. Pediatrics 2006; 117: 2222-30.

6 Tiruvoipati R, Balasubramanian SP, Peek GJ, Elbourne D. Improving the quality of reporting randomized controlled trials in cardiothoracic surgery: the way forward. J Thorac Cardiovasc Surg 2006; 132: 233-40.

7 Montori VM, Perri D, Mother D, Guyatt G. Determining the reporting quality of RCTs in clinical pharmacology. Br J Clin Pharmacol 2004; 58: 61-5.

8 Higgins JPT, Green S, eds. Selection Bias. Cochrane Handbook for Systematic Reviews of Interventions 4.2.5 [updated May 2005]; Section 6, pp. 80-1. In: The Cochrane Library, issue 3. Chichester: John Wiley \& Sons, Ltd, 2005. 